\title{
Influenza vaccination of hospital staff in Germany: a five-year survey on vaccination coverage and policies: identified deficits in influenza immunisation campaigns for hospital employees
}

\author{
Submitted: 4 July 2003 \\ Accepted: 6 May 2004
}

Summary

Objectives: Influenza vaccination of hospital staff is recommended by STIKO, the German committee for vaccination. A survey was conducted to assess compliance with this recommendation. The occupational health services of 25 hospitals participated in a survey and provided data by questionnaire on influenza vaccination and on hospital policies to promote coverage of employees.

Methods: Vaccination activities were monitored by occupational health services (OHS) for five consecutive years from 1997 to 2002. The hospital sample covered a total of 17089 beds ( $3.23 \%$ of the hospital capacity in Germany) and a total number of 41969 employees (4.39\% of hospital staff).

Results: The proportion of hospitals actively offering in fluenza vaccination increased from $48 \%$ in $1997 / 98$ to $92 \%$ in 2001/02. Vaccination coverage of all staff in 1997 was only $3.3 \%$ and reached $8.4 \%$ in 2001/02. Coverage of vaccinating hospitals increased from $5.0 \%$ to $10.4 \%$. Poster campaigns and managing board commitment had significant impact.

Conclusions: Considerable progress has been made to involve more hospitals and to increase coverage for vaccination of hospital employees. Nevertheless, coverage levels remain unacceptably low. Recommendations are ignored extensively.

Keywords: Influenza vaccination - Hospital staff - Vaccination coverage - Occupational health services - Germany - STIKO recommendation.

For many years, both the Robert Koch Institute (RKI) and the Advisory Committee on Immunization Practices
(ACIP) of the Centers for Disease Control and Prevention (CDC) have emphasized the special need for medical personnel to be vaccinated against influenza (Robert Koch Institut 2001; Bridges et al. 2002). Both authorities demand that this group should be among the first to be vaccinated in case of shortage of vaccine (Advisory Committee on Immunization Practices 2001; Fock 2001). Among the many reasons for this recommendation, the reduction of patients' mortality as shown in studies, conducted in long-term care hospitals (Potter et al. 1997; Carman 2000) - should be regarded as sufficient incentive for high vaccination coverage of hospital staff. Potter et al. (1997) found a reduction in total patient mortality in long-time care hospitals for the elderly from $17 \%$ (with approximately less than $3 \%$ of the staff being vaccinated) to $10 \%$ (with $61 \%$ of the staff being vaccinated before the season). It is also interesting to note that, in the same study, vaccination of the elderly patients themselves was not found to have a significant effect on their mortality. The study by Carman et al. (2000) had similar results: Patient mortality in institutions with no vaccination policy for personnel was $22.4 \%$ (although $4.8 \%$ of them had been vaccinated outside and $33 \%$ of the patients were vaccinated), while the vaccinated group only showed $13.6 \%$ (with $50.9 \%$ of the personnel and $48 \%$ of the patients vaccinated).

Other important reasons for influenza vaccination of medical personnel are the demand to secure a functional healthcare system, particularly in times of an influenza pandemic and the individual protection of the health care workers and their families. The emergence of severe acute respiratory syndrome (SARS) in 2003, might contribute to this consideration. Both diseases seem to have similar modes of transmission. Evaluations of the worldwide SARS outbreak showed, that health care workers were among the most affected. Lee 
et al. (2003) reported that out of 138 SARS patients in an outbreak in Hong Kong 69 were health care workers (50\%) and 16 medical students (11\%). The same study showed in spite of precaution measures the occurrence of tertiary cases among family members of health care workers. Booth et al. (2003) showed similar figures of 73 health care workers among 144 SARS patients (51\%) in an outbreak in the area of Toronto. Health care workers clearly face a higher risk of acquired respiratory infections like influenza and SARS.

The cost-effectiveness of influenza vaccination of healthy working adults mainly as a result of the high costs of working time lost through influenza has been well documented and reviewed (Postma et al. 2002).

Taking all these advantages into consideration, it should be expected that most of the hospital workers are vaccinated. But what is the actual situation? When this survey was started, only very little data on influenza vaccination coverage for medical personnel in Germany were available. We therefore conducted a survey to obtain data on influenzavaccination-coverage in German hospitals.

\section{Methods}

The survey was conducted as a questionnaire-based study on influenza vaccination in German hospitals for acute care in the period of five consecutive winter seasons from 1997/98 to 2001/02. The participants were recruited from two occupational medicine training courses, which took place in July and September 2000 in Dresden and Munich. The recruitment of the hospitals by inviting attendees of training courses to participate in the survey, was preferred, as recruitment of representative hospital samples by mail usually result in very poor response rates. The training courses included 58 physicians in charge of occupational health of hospitals who received a detailed questionnaire in September 2000. The questionnaire asked for information about the hospital and its staff, the number of employees vaccinated against influenza during the seasons 1997/98, 1998/99 and 1999/2000 by the hospital's Occupational Health Services (OHS), strategies to vaccinate the employees, and media application to inform them about the vaccination offered and the advantages of it.

In June 2002 the OHS doctors, who had returned the questionnaire, were contacted again and asked for the number of employees vaccinated in the two subsequent seasons, 2000/01 and 2001/02, and if the number of employees had changed significantly since 2000 .

\section{Results}

\section{Sample size}

25 of $58(43.1 \%)$ questionnaires were returned. The responding sample covered $1.24 \%$ of all German hospitals in 1999 as given in Gerste et al. (2002). Hospital size among those examined ranged from 205 to 1971 beds, with a mean of 703 and a median of 558. The hospital sample enclosed a total of 17089 beds, which corresponds to $3.23 \%$ of the bed capacity of German hospitals in 1999 as reported by Gerste et al. (2002). The hospitals were divided into three groups, according to their size, resulting in eight major hospitals (with more than 800 beds), nine medium-sized hospitals (with 400 to 799 beds) and eight small hospitals (with less than 400 beds) (see Fig. 1).

The number of hospital employees in 1999 ranged between 375 and 6380 (mean: 1679; median: 1250). Altogether, the sample covered 41969 employees, corresponding to $4.39 \%$ of all employees in German acute care hospitals in 1999 as
Figure 1 Distribution of hospital size by number of beds

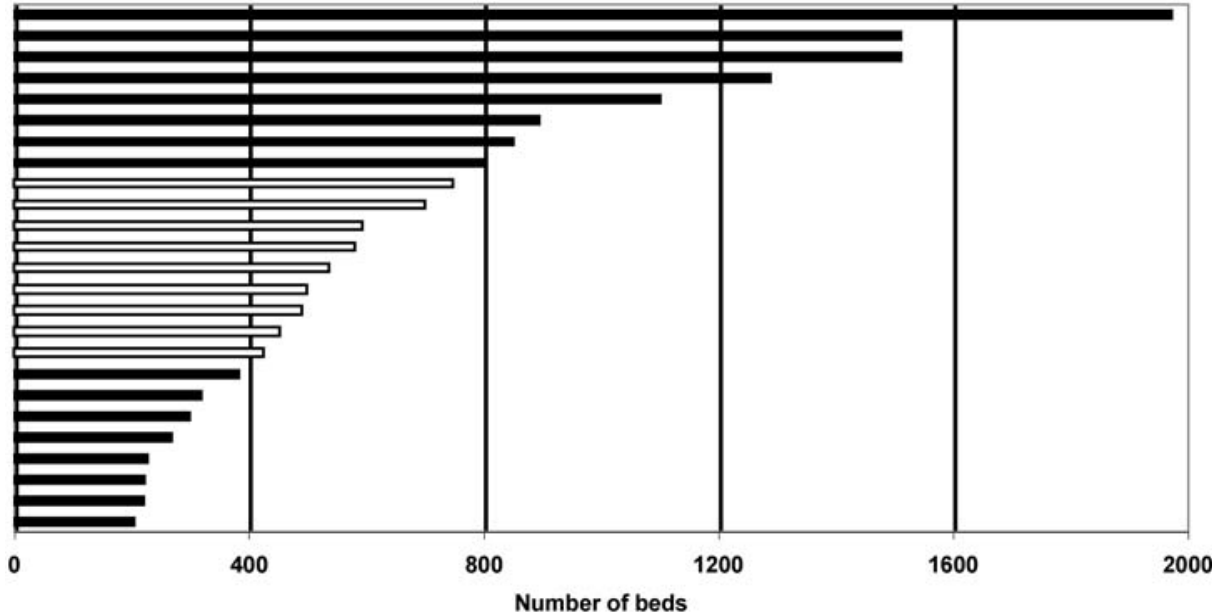


shown by Gerste et al. (2002). Geographical distribution showed representative participation of hospitals from the former East (5) and West (20) Germany.

\section{Vaccination policy}

Of the 25 hospitals participating, 12 were already offering free influenza vaccinations to their employees in 1997/98. In $1999 / 2000$ another four started such a policy and in 2000/01 a further six followed. Of the remaining three, another has started offering vaccinations in the season 2002/03 whereas only two were not providing vaccinations to their personnel. All hospitals offering vaccination did so during working hours of the employees, mostly at the site of the OHS, while in three cases, even on the wards.

Half of the eight major hospitals already had a vaccinationpolicy in 1997/98 and since 2000/01 all eight of them have offered vaccination. Of the medium-sized ones, three out of nine offered it in 1997/98, two more started in 1999/2000 and another three in 2000/01. One has still not implemented a vaccination program. Five of the eight small hospitals offered vaccination in 1997/98, one more started 1999/2000 and another one was about to start in the season 2002/03.

Of the five institutions in the former East Germany, only two vaccinated their staff in $1997 / 98$. One more started in the 2000/01-season and one of the remaining two has started vaccination in the season 2002/03. In the former West Germany, half of the 20 hospitals vaccinated their workforce in $1997 / 98$. During the 1999/2000 season, another four, and one season later five others, joined the vaccination group. Figure 2 shows the increase in hospitals providing vaccinations from $48 \%$ in 1997 to $92 \%$ in 2002 .

\section{Vaccination coverage}

While the total number of people employed by the 25 hospitals changed only slightly from 41969 in 1999 to 42233 in 2002 , the number of people vaccinated annually by the OHS more than doubled. Administered vaccinations rose from 1380 in 1997/98 to 3535 in the past season. This indicates an increase of coverage from $3.3 \%$ to $8.4 \%$ (see Fig. 3 ). The subgroup of hospitals which were already vaccinating in 1997/98 at that time gave 1334 vaccinations to their 24993 employees, which corresponds to a coverage of $5.3 \%$. In 2001/02 the same hospitals vaccinated 2521 $(10.6 \%)$ of their 23809 employees. Because the major hospitals vaccinated proportionally more employees in this subgroup than the small ones, the average of the mean coverage rates are a little lower: $5.0 \%$ in $1997 / 98$ and $9.4 \%$ in $2001 / 02$. Not only the number of vaccinating hospitals increased during the survey period, but the average vaccination-coverage of the growing number of vaccinating hospitals also increased: $5.0 \%$ in $1997 / 98 ; 6.6 \%$ in $1998 / 99 ; 8.4 \%$ in $1999 / 2000 ; 10.1 \%$ in $2000 / 01$ and $10.4 \%$ in $2001 / 02$. The growth in coverage rates is summarized in Table 1. Hospitals did not monitor and provide individual data like job categories of vaccinated staff. Therefore the coverage rate has been established for hospital staff in general.

\section{Factors influencing the vaccination rate}

Hospital size had no significant impact on the vaccination policy, nor did the duration of the vaccination policy. Newcomers usually achieved average values in their first season. The best coverage result was reached with $21.2 \%$ of the employees vaccinated by a hospital in its first year of influenza vaccination!
Figure 2 Increase of percentage of vaccinating hospitals during the five-year survey period

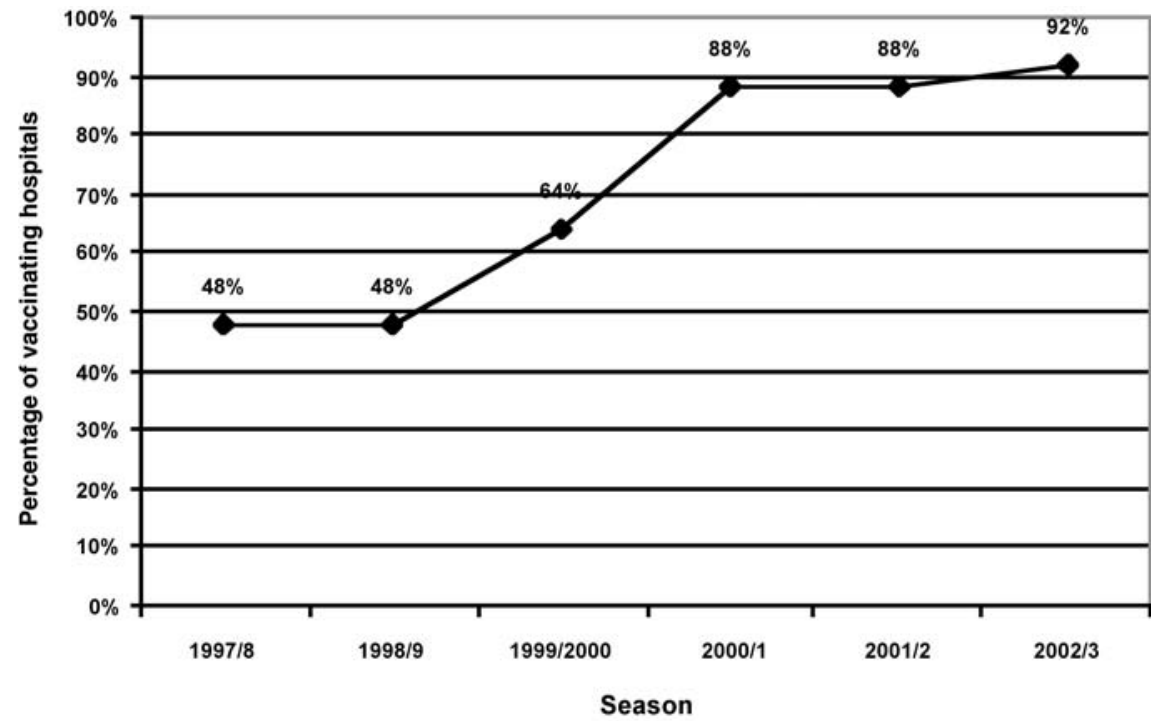


Figure 3 Vaccination coverage of hospital employees as a percentage of the total number of employees

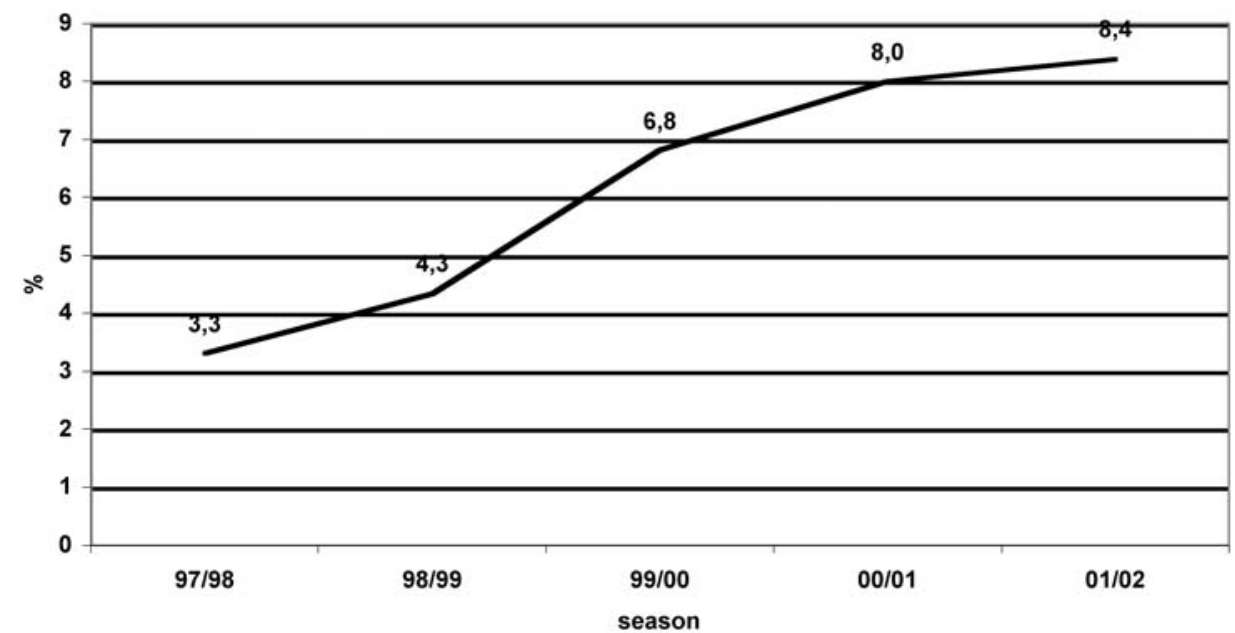

Table 1 Vaccination coverage rates for subgroups of our sample

\begin{tabular}{llcl}
\hline & $\begin{array}{l}\text { Period } \\
\mathbf{1 9 9 7 / 9 8}\end{array}$ & $\begin{array}{l}\text { Period } \\
\mathbf{2 0 0 1 / 0 2}\end{array}$ & $\begin{array}{l}\text { Growth } \\
\text { rate }\end{array}$ \\
\hline $\begin{array}{l}\text { Total vaccination coverage } \\
\text { of all employees }\end{array}$ & $3.3 \%$ & $8.4 \%$ & $154.5 \%$ \\
$\begin{array}{l}\text { Coverage rate of the } \\
\text { employees of the 12 hospitals, } \\
\text { vaccinating already in 1997 }\end{array}$ & $5.3 \%$ & $10.6 \%$ & $100 \%$ \\
$\begin{array}{l}\text { Average of mean coverage } \\
\text { rate of the 12 hospitals } \\
\text { vaccinating already in 1997 }\end{array}$ & $5.0 \%$ & $9.4 \%$ & $88 \%$ \\
$\begin{array}{l}\text { Average of mean coverage } \\
\text { rate of all vaccinating hospitals }\end{array}$ & $\begin{array}{l}5.0 \% \\
(n=12)\end{array}$ & $\begin{array}{l}10.4 \% \\
(n=22)\end{array}$ & $108 \%$ \\
\hline
\end{tabular}

The number of weeks employees were offered the vaccine did not influence the results in a significant way. Two sites with very good results, for example, had only a six-week vaccination program, while many less successful ones even offered a vaccination program extending over four or five consecutive months annually.

Only three OHSs offered to vaccinate the ward staff at their working site with only one hospital having comparatively high success: This was the one achieving $21.2 \%$ in the first season.

For promotional purposes, 16 institutions with vaccination programs used widespread media like posters in main areas,

Table 2 Media application and support of the managing board members

\begin{tabular}{|c|c|c|c|}
\hline & $\begin{array}{l}\text { Group with } \\
\text { low coverage } \\
(<5 \%) \\
(n=5)\end{array}$ & $\begin{array}{l}\text { Group with } \\
\text { higher coverage } \\
(>5 \%) \\
(n=11)\end{array}$ & $x^{2}$ \\
\hline Use of posters in central places & $1 / 5$ & 9/11 & $0.018^{\mathrm{a}}$ \\
\hline Use of posters at the site of the OHS & $2 / 5$ & 11/11 & $0.004^{\mathrm{a}}$ \\
\hline Use of posters on the wards & $1 / 5$ & 10/11 & $0.005^{\mathrm{a}}$ \\
\hline Information in employee's newspapers & $3 / 5$ & $5 / 11$ & 0.590 \\
\hline Distribution of information material to all employees & $2 / 5$ & $7 / 11$ & 0.377 \\
\hline Personal invitation by letter to every employee & $1 / 5$ & $1 / 10$ & 0.541 \\
\hline Personal invitation by email//ntranet & $0 / 5$ & $1 / 10$ & 0.486 \\
\hline Sufficient technical literature on the topic & $2 / 5$ & $7 / 11$ & 0.377 \\
\hline Medical director taking part in the vaccination & $0 / 5$ & $5 / 11$ & 0.069 \\
\hline Administrative director taking part in the vaccination & $0 / 5$ & $4 / 11$ & 0.119 \\
\hline Nursing director taking part in the vaccination & $0 / 5$ & $7 / 11$ & $0.017^{\mathrm{b}}$ \\
\hline Medical director supporting the campaign & $0 / 5$ & $5 / 11$ & 0.069 \\
\hline Administrative director supporting the campaign & $1 / 5$ & $5 / 11$ & 0.330 \\
\hline Nursing director supporting the campaign & $0 / 5$ & $7 / 11$ & $0.017^{b}$ \\
\hline Board members taking part in the vaccination & $0 / 15$ & $16 / 33$ & 0.001 \\
\hline Board members supporting the campaign & $1 / 15$ & $17 / 33$ & 0.008 \\
\hline
\end{tabular}

1 Statistically significant, but in three of the four fields of the crossing-table, less than five cases were given

2 Statistically significant, but in two of the four fields of the crossing-table, less than five cases were given 
at the OHS office and/or on the wards. Some used brochures or hospital internal employee newspapers, while five used personal invitations either by letter or e-mail. The use of media and the support of the managing board was assessed for the 1999/2000 season, in which 16 hospitals were vaccinating. Differences between hospitals below and above $5 \%$ coverage were statistically analyzed. $5 \%$ coverage represents the average rate at the start of the survey. The results are presented in Table 2.

The specific types of promotion had seemingly no major impact on vaccination coverage. Success could not be guaranteed by either combining as many of the advertising approaches as possible or using one particular method. Obviously the use of occupational health posters at OHS and on the wards was an inevitable part of the campaign.

Support and vaccination status of managing board members was unequally distributed between high and low coverage hospitals. The impact of more engagement by board members was statistically highly significant.

\section{Discussion}

Influenza vaccination of hospital staff is required for disease prevention and protection of patients and has also been shown to be cost effective (Hallauer \& Rode 1999). It is therefore recommended by the STIKO (German committee for vaccination) of the RKI. Data on compliance with this advice are very limited. Results from two public telephone surveys conducted by the RKI in Stuttgart in 1998 and in Berlin in 1999, showed coverage rates among health care workers of between $7.4 \%$ and $10.5 \%$. (Robert Koch Institute 1998; 1999). However, these did not differentiate between hospital and non-hospital staff. Due to the very small number of health personnel included in these studies - 57 individuals in 1998 and 81 in 1999 - conclusions resulting from these studies were limited. We therefore focused our survey specifically on hospital staff directly monitored by occupational health services. To avoid limitations due to measuring coverage rates at only one point of time, we also carried out a longitudinal study thus observing trends. Our mode of recruitment may be bi-ased in favor of higher coverage rates, as attendees of the OHS training courses are assumingly more interested in the topic of influenza vaccination. The participating physicians were possibly the more interested and engaged. On the other hand, a representative recruitment procedure faces the same selection bias, if response rates are not excellent. Our sample of 25 hospitals might have it's limitation in re-spect of representativeness due to its size and selection, but anyhow showed being well distributed regarding hospital size and geographical spread. Results the- refore cannot be seen as the national average, nonetheless provide a reasonable approach to identify deficits. All participating hospitals provided data for five consecutive years. Results were consistent for individual hospitals showing a substantial increase in coverage (108\%) for the total of vaccinating sites. The range of coverage rates from $0.4 \%$ to $21.2 \%$ indicate that no hospital was able to obtain an acceptable level. Despite the alarmingly overall low levels, the number of hospital employees who had been vaccinated increased from 1997 to 2001 by $154.5 \%$. Furthermore, the number of hospitals actively offering vaccination nearly doubled in these five years. The 2001/2002 mean coverage rate of $10.4 \%$ of the hospitals of our sample meets the results of a recently published RKI telephone survey (Robert Koch Institute 2002) reporting a $7 \%$ influenza vaccination rate among West German health care workers.

A questionnaire-based study, published by Buchholz et al. (2002), reported a vaccination rate of $16 \%$ among 886 physicians and nursing staff of 25 German hospitals. The rates for the last two seasons found in our survey are somewhat lower than those described by Buchholz. This might be due to the fact that we examined only the vaccination figures provided by the OHS, which did not include possible vaccinations carried out by family doctors. No hospital in our sample recorded information about vaccinations administered elsewhere. Additionally, our coverage rates are calculated for the entire hospital staff whereas Buchholz included medical and nursing staff only.

It is believed, that vaccination campaigns can increase coverage. Little evaluation is available on impact of certain promotion elements for influenza vaccination of health care workers. A failure of a promotional campaign has been demonstrated by Dey et al. (2001). Our findings suggest that standard OHS poster as well as commitment of the hospital management board play a major role in enhancing influenza vaccination coverage.

Considering similar routes of infection and target population of influenza and SARS and problems of differential diagnosis special emphasis should be given to vaccination of health care workers (Lübbert et al. 2003).

In summary, our results on hospital employees are in line with population-based telephone surveys and the recent medical staff study revealing dramatic ignorance towards influenza prevention in German hospitals, in particular if possible recruitment bias is taken into account. More efforts are needed to successfully implement influenza vaccination of hospital staff to enjoy the benefits mentioned. The lack of compliance with prevention guidelines is unacceptable even in view of the generally high reluctance of Germans to be vaccinated, compared to e.g., the United States, where the 
health care workers reached "only" a $34 \%$ influenza coverage rate in 1997 and $38 \%$ in 2000 (Bridges et al. 2002), which resulted in harsh self-criticism in the country.

\section{Acknowledgements}

The authors wish to thank among others the following colleagues for providing data from their hospitals: Dr. G. Beck- mann, Dr. H. Schopper, Dr. M. Stichert, Dr. A. Rauch, Dr. M. Gotzmann, Dr. F. Nitzsche, Dr. B. Kühnl, Dr. C. Kaden, Dr. W. Keßler-Rode, Dr. A. Vasicek-Kunde, Dr. U. Schmidt, Dr. R. Noeken
Zusammenfassung

Influenzaimpfung von Krankenhauspersonal in Deutschland: eine Fünfjahresuntersuchung zu Durchimpfungsraten, Impfpolitik und -defiziten in $\mathbf{2 5}$ deutschen Krankenhäusern

Fragestellung: Die Impfung von Krankenhauspersonal gegen Influenza wird von der Ständigen Impfkommission (STIKO) empfohlen. Die Umsetzung dieser Empfehlung in deutschen Krankenhäusern wurde untersucht. Die Betriebsärzte von 25 Krankenhäusern nahmen an einer Umfrage teil, für die sie Daten ihres jeweiligen Hauses zur Influenzaimpfung und Impfpolitik bereitstellten.

Methode: Die Untersuchung fand in fünf aufeinander folgenden Jahren (1997-2002) statt. Die Stichprobe umfasste insgesamt 17089 Betten (3,23\% der gesamten deutschen Bettenkapazität) und 41969 Angestellten (4,39\% des deutschen Krankenhauspersonals).

Ergebnisse: Der Anteil der impfenden Krankenhäuser stieg von $48 \%$ in der Saison 1997/98 auf $92 \%$ in 2001/02. Die Durchimpfungsrate lag 1997 bei nur 3,3\% und 2001/02 erreichte sie $8,4 \%$. Die Impfrate in impfenden Krankenhäusern stieg im gleichen Zeitraum von 5,0\% auf 10,4\%. Poster-Kampagnen und Einbeziehung der Krankenhausleitung haben signifikanten Einfluss.

Schlussfolgerung: Es zeigt sich eine deutliche Steigerung sowohl der Krankenhäuser mit Impfangebot als auch der Durchimpfungsrate des Krankenhauspersonals. Nichtsdestotrotz bleibt diese aber auf einem nicht akzeptabel niedrigem Niveau.
Résumé

Vaccination contre la grippe du personnel hospitalier en Allemagne: une recherche de cinq ans sur les taux de vaccination et la politique appliquée en matière de vaccination dans 25 hôpitaux allemands

Objectifs: La vaccination du personnel hospitalier contre la grippe est recommandée par la Commission permanente de la vaccination du Robert Koch Institut. Cette étude a porté sur I'application de cette recommandation dans les hôpitaux allemands. Les médecins du travail de 25 hôpitaux ont participé à une enquête dans le cadre de laquelle ils ont fourni les données suivantes: prévalence de la vaccination contre la grippe et méthodes de promotion de la vaccination.

Méthodes: L'enquête a eu lieu cinq années consécutives (1997-2002). Elle a porté sur 25 hôpitaux, soit sur 41969 employés (4,39\% du personnel hospitalier allemand).

Résultats: La proportion d'hôpitaux pratiquant la vaccination est passée de $48 \%$ pour la période $1997 / 98$ à $92 \%$ pour 2001/02. En 1997, le taux de vaccination ne s'élevait qu'à 3,3\% pour atteindre $8,4 \%$ en $2001 / 02$. Le taux de vaccination dans les hôpitaux pratiquant déjà la vaccination en 1997 est passé durant la même période de 5,0\% à 10,4\%. L'implication de la direction hospitalière ainsi que le recours à des affiches ont eu un impact significatif.

Conclusions: Le nombre d'hôpitaux proposant la vaccination, ainsi que le taux de vaccination ont nettement augmenté. Néanmoins, ce taux reste à un niveau inacceptablement bas. 


\section{References}

Advisory Committee on Immunization Practices (2001). Delayed influenza vaccine availability for 2001-02 season and supplemental recommendations of the Advisory Committee on Immunization Practices. MMWR Morb Mortal Wkly Rep 50: 582-5.

Booth CM, Matukas LM, Tomlinson GA, et al. (2003). Clinical features and short-term outcomes of 144 patients with SARS in the greater Toronto area. JAMA 289: 2801-9.

Bridges CB, Fukuda K, Uyeki TM, Cox NJ, Singleton JA (2002). Prevention and control of influenza: recommendations of the Advisory Committee on Immunization Practices (ACIP). MMWR Recomm Rep 51(RR-03): 1-31.

Buchholz U, Haas W, Kramer MH (2002). Influenza-Impfung bei medizinischem Personal: überraschende Defizite in deutschen

Krankenhäusern. Dtsch Ärztebl 99: A-2460/ B-2100/C-1968.

Carman WF, Elder AG, Wallace LA (2000). Effects of influenza vaccination of health-care workers on mortality of elderly people in longterm care: a randomised controlled trial. Lancet 355: 93-7.

Dey $P$, Halder S, Collins S, Benon L, Woodman C (2001) Promoting uptake of influenza vaccination among health care workers: a randomized controlled trial. J Public Health Med 23: 346-8.
Fock R (2001). Influenza-Pandemie Planung für Deutschland. 10. Internationales Wartburg Kolloquium, 10. October. 2001.

Gerste B, Schellschmidt H, Rosenow C (2002). Personal im Krankenhaus: Entwicklungen 1991 bis 1999. In: Arnold M, Klauber J, Schellschmidt H, eds. Krankenhaus-Report 2001. Stuttgart: Schattauer: $13-46$.

Hallauer JF, Rode M (1999). Gesundheitliche und ökonomische Auswirkungen der Influenza und Influenza-Schutzimpfung. Immunol Impfen 2: $140-5$.

Lee N, Hui D, Wu A, et al. (2003) A major outbreak of severe acute respiratory syndrome in Hong Kong. N Engl J Med 348: 1986-94.

Lübbert C, Grünewald T, Gottschalk R, Kurth R, Ruf BR (2003). Respiratorische Virusinfektionen/ Klinische Differentialdiagnose/Ein Algorithmus kann die Unterscheidung von Influenza, „grippalem Infekt" und SARS erleichtern. Dtsch Ärzteblatt 100: A3143-6.

Postma MJ, Jansema P, van Genugten $M L$, Heijnen ML, Jager JC, de Jong-van den Berg LT (2002). Pharmacoeconomics of influenza vaccination for healthy working adults - reviewing the available evidence. Drugs 62: 1013-24.

Potter J, Stott DJ, Roberts MA, et al. (1997). Influenza vaccination of health care workers in long-term-care hospitals reduces the mortality of elderly patients. J Infect Dis 175: 1-6.
Robert Koch Institut (1998). Wie wurde das Angebot der Influenza-Schutzimpfung im Herbst 1998 angenommen? Ergebnisse einer Querschnittsuntersuchung zu Impfraten in der Berliner und Stuttgarter Bevölkerung. Epidemiol Bull 50: 356-8.

Robert Koch Institut (1999). Beteiligung an der Influenza-Schutzimpfung in der Saison 1999/2000: Ergebnisse einer bundesweiten Querschnittsstudie. Epidemiol Bull 50: 377-81.

Robert Koch Institut (2001). Impfempfehlungen der Ständigen Impfkommission (STIKO) am RKI, Stand Juli 2001. Epidemiol Bull 28: 203-18.

Robert Koch Institut (2002). Teilnahem an Influenza- und Pneumokokken- Schutzimpfung: bundesweite Querschnittsstudie zur Situation in der Saison 2001/2002. Epidemiol Bull 16: 127-34.

Address for correspondence

Dr. med. Johannes F. Hallauer

Charité Universitätsmedizin Berlin

Campus Charité Mitte

Gesundheitssystemforschung

Schumannstrasse 20/21

D-10117 Berlin

Tel.:+49 30450570231

Fax:+49 30450570971

e-mail: johannes.hallauer@charite.de 